\title{
O ESPAÇO DO DOMICÍLIO COMO LÓCUS DA ATIVIDADE EMPREENDEDORA: UM ESTUDO SOBRE OS EMPREGADORES DOMICILIARES NO BRASIL CONTEMPORÂNEO
}

\author{
Alessandro Gomes Enoque - Universidade Federal de Uberlândia ${ }^{1}$ \\ Alex Fernando Borges - Universidade Federal de Lavras ${ }^{2}$
}

Resumo: Tendo em vista a relevância de estudos que buscam compreender a dinâmica da atividade empreendedora locada no espaço do domicílio, o presente trabalho teve como objetivo traçar um perfil dos empregadores domiciliares no Brasil contemporâneo. Entendidos como aqueles indivíduos com idade entre 15 e 65 anos, residentes no meio urbano, que exercem atividades produtivas no espaço do domicílio e que contam com a ajuda de empregados, os empregadores domiciliares foram comparados com outras categorias de referência (empregadores em atividade não-domiciliar e trabalhadores domésticos). Tal comparação, instrumentalizada por uma série histórica retirada das Pesquisas Nacionais por Amostra de Domicílios (PNAD's) e analisada através da utilização de software estatístico (SPSS), possibilitou uma melhor compreensão da natureza deste tipo de atividade inserida nas tramas do tecido produtivo brasileiro. Foi possível compreender este tipo de atividade (empregador domiciliar) como sendo de natureza tipicamente masculina, branca, com alto grau de escolaridade (no comparativo com o restante da população brasileira) e com faixa etária elevada. Além disto, este grupo tem uma média de trabalho semanal elevada (48,17 horas), pouco contribuindo para o desempenho das atividades domésticas (17,42 horas semanais em média), com um tempo médio de permanência como empregadores domiciliares da ordem de 9,37 anos.

Palavras-chave: Empreendedorismo, Empreendedor, Empregador Domiciliar.

\section{HOUSEHOLD SPACE AS LOCUS OF ENTREPRENEURIAL ACTIVITIES: A STUDY OF HOUSEHOLD EMPLOYERS IN BRAZIL}

Abstract: Given the importance of studies that seek to comprehend the dynamics of home-based entrepreneurial activities, this paper aims to map the profile of household employers in Brazil. Seen as those individuals aged between 15 to 65 years old who lives in urban areas and exert home-based productive activities, household employers were compared with other categories (such as business employers and domestic workers). In order to do so, we used an historical series based on National Household Sample Research (PNAD's), which were analyzed through statistical software (SPSS), enabled a better understanding of the nature of this type of activity (household employers) as typically male, white, with high level of

\footnotetext{
${ }^{1}$ E.mail: alessandroenoque@pontal.ufu.br - Endereço: Av. João Naves de Ávila, 2121 - Santa Mônica, Uberlândia - MG, CEP: 38408-100.

2 E.mail: alexfborges@gmail.com
}

ENOQUE, A. G.; BORGES, A. F. O espaço do domicílio como lócus da atividade empreendedora: um estudo sobre os empregadores domiciliares no Brasil contemporâneo. Revista de Empreendedorismo e Gestão de Pequenas Empresas, v. 3, n.1, p. 105-128, 2014. 
education (comparing with rest of the Brazilian population) and higher ages. In addition, this group has a high working week average (48.17 hours), contributing little to domestic activities (17.42 hours a week in average), and with 9.37 years as household employers in average.

Keywords: Entrepreneurship, Entrepreneur, Household Employer.

\section{Introdução}

É fato comumente aceito que a temática do empreendedorismo tem estado presente, de maneira marcante, no vocabulário de diversas áreas do conhecimento científico. Essa amplitude, em parte credora dos processos de reestruturação produtiva ocorridos nos países desenvolvidos no período pós-década de 1980 e de um crescimento numérico de tal atividade no Brasil e no mundo, tem gerado inúmeras discussões acerca dos aspectos conceituais e metodológicos ligados ao termo.

A difusão do termo empreendedorismo tem sido observada em diferentes áreas do conhecimento científico, e em diferentes dimensões da prática empresarial. Não obstante, tal difusão se caracterizou por uma significativa confusão teóricoconceitual, uma vez que os limites para a apreensão desse fenômeno ainda não foram adequadamente estabelecidos pela academia (CORNELIUS; LANDSTRÖM; PERSSON, 2006). Em conformidade com esta perspectiva, Shane (2000) destaca a necessidade de construção de um arcabouço conceitual consistente que auxilie no processo de legitimação do empreendedorismo enquanto um campo de conhecimento científico específico. Assim, verifica-se a configuração de um desafio, na medida em que torna-se necessário compreender cientificamente as particularidades e problemáticas específicas associadas ao fenômeno do empreendedorismo.

As dificuldades referentes ao tema não geram, no entanto, imobilidade. Ao contrário, suscitam uma série de questões relevantes que podem contribuir, sobremaneira, na compreensão da dinâmica do empreendedorismo no Brasil e no mundo. Com efeito, Ruppenthal e Cimadon (2012) reiteram que o Brasil tem se posicionado como um dos líderes na manifestação do fenômeno do empreendedorismo. Essa realidade, segundo os autores, pode ser compreendida a

ENOQUE, A. G.; BORGES, A. F. O espaço do domicílio como lócus da atividade empreendedora: um estudo sobre os empregadores domiciliares no Brasil contemporâneo.

Revista de Empreendedorismo e Gestão de Pequenas Empresas, v. 3, n.1, p. 105-128, 2014. 
partir de duas perspectivas: por um lado, tal fato configura-se como um sinal de crescimento econômico, da existência de um ambiente propício à criação de empresas e composto por novas oportunidades de negócio; por outro lado, uma análise mais cuidadosa reflete a configuração de um empreendedorismo por necessidade, caracterizado sobretudo pela busca de ocupação e renda. Neste último cenário, inserem-se iniciativas de microempreendedores e empregadores domiciliares.

Procura-se, portanto, lançar luzes sobre um grupo de empreendedores que, normalmente, não é visualizado pelas estatísticas oficiais nem pelos formuladores de políticas públicas, além de ser pouco estudado na academia. Sendo assim, o presente trabalho possui o objetivo de traçar um perfil dos empregadores domiciliares no Brasil contemporâneo. Os empregadores domiciliares, entendidos neste trabalho como aqueles indivíduos (com idade entre 15 e 65 anos e residentes no meio urbano) que desenvolvem atividades produtivas no universo da casa e que contam com a colaboração de empregados, consistem em um grupo tradicionalmente obscurecido nas pesquisas acadêmicas e carecem, neste sentido, de maior compreensão.

Este trabalho será estruturado nas seguintes seções, além desta introdução: Empreendedorismo; Procedimentos Metodológicos; Atividade Empreendedora e o Empregador Domiciliar: Análise da Realidade Brasileira; Considerações Finais; e, por fim, Referências.

\section{Empreendedorismo}

As primeiras referências à palavra empreendedorismo podem ser encontradas no contexto francês do século XVI (MARTINELLI, 1994). Para o autor, o termo referia-se, naquele momento, ao "[...] capitão de fortuna que contratava soldados mercenários para servir príncipes ou cidades em troca de pagamento". Em uma perspectiva semelhante, Tripathi (1985), argumenta que a palavra estava associada, neste primeiro momento, à figura do líder de uma expedição militar e não possuía conotação positiva ou prestigiosa.

ENOQUE, A. G.; BORGES, A. F. O espaço do domicílio como lócus da atividade empreendedora: um estudo sobre os empregadores domiciliares no Brasil contemporâneo. Revista de Empreendedorismo e Gestão de Pequenas Empresas, v. 3, n.1, p. 105-128, 2014. 
Foi apenas a partir do século XVIII que o termo ultrapassou os limites da área militar e instaurou-se no campo dos atores econômicos. Neste sentido, a palavra empreendedorismo representava os indivíduos que introduziam novas técnicas agrícolas em suas terras ou que arriscavam seu próprio capital na indústria, bem como aqueles que eram subcontratados para executar obras públicas como pontes e estradas.

Um dos primeiros autores normalmente identificados com o campo do empreendedorismo foi Richard Cantillon (FILION, 1999). Para Cantillon, empreendedor seria aquele indivíduo que compra matéria-prima por um preço certo para revendê-la a preço incerto (GOMES; LIMA; CAPPELLE, 2013). É interessante notar que a definição proposta por Cantillon possui um caráter bastante abrangente, uma vez que pode incluir, no rol dos empreendedores, todos aqueles indivíduos envolvidos em uma atividade econômica, excetuando-se os representantes do poder público, os proprietários de terra e os assalariados. Além disto, conforme apontado por Filion (1999, p.07), os empreendedores, na perspectiva de Cantillon, seriam aquelas "[...] pessoas que aproveitavam as oportunidades com a perspectiva de obterem lucros, assumindo os riscos inerentes".

De acordo com Filion (1999), Jean-Baptiste Say foi o segundo autor a demonstrar interesse pelo fenômeno do empreendedorismo, ao distinguir dois grupamentos ocupacionais específicos: capitalistas e empreendedores. No que diz respeito aos últimos, Jean-Baptiste Say associava-os fortemente à dimensão da inovação e da mudança, entendendo que os mesmos contribuiriam significativamente para o desenvolvimento econômico dos países. É interessante observar, no entanto, que esta triangulação entre inovação, empreendedorismo e desenvolvimento econômico pode ser observada, de forma mais efetiva, nos trabalhos de Schumpeter (1982). Em sua obra seminal, "A Teoria do Desenvolvimento Econômico", o autor austríaco lançou as bases de uma moderna teoria do empreendedorismo e seu importante papel no desenvolvimento econômico dos diversos países.

Para Schumpeter (1997), a vida econômica seguiria um fluxo circular, que corre essencialmente pelos mesmos canais ano após ano. $\mathrm{O}$ autor distingue, neste

ENOQUE, A. G.; BORGES, A. F. O espaço do domicílio como lócus da atividade empreendedora: um estudo sobre os empregadores domiciliares no Brasil contemporâneo.

Revista de Empreendedorismo e Gestão de Pequenas Empresas, v. 3, n.1, p. 105-128, 2014. 
sentido, dois conceitos inteiramente distintos que são, respectivamente, crescimento (econômico) e desenvolvimento econômico. Para Schumpeter (1997), a ideia de crescimento econômico estaria associada ao aumento da população e da riqueza de determinada sociedade. Tal fenômeno, embora importante, não suscitaria nada qualitativamente novo, mas apenas processos de adaptação de uma mesma espécie. A dimensão do desenvolvimento econômico, ao contrário, seria um fenômeno inteiramente distinto e estranho ao comportamento equilibrado (fluxo circular) de determinada economia. Para Schumpeter (1997), esta mudança revolucionária, que teria origem privilegiada nas esferas industrial e comercial (e não no gosto dos consumidores), alteraria e deslocaria para sempre o estado de equilíbrio pré-existente:

[...] é o produtor que, via de regra, inicia a mudança econômica, e os consumidores são educados por ele, se necessário; são, por assim dizer, ensinados a querer coisas novas, ou coisas que diferem em um aspecto ou outro daquelas que tinham o hábito de usar. (SCHUMPETER, 1997, p.48).

É dentro deste escopo que o autor insere a temática da inovação e sua íntima associação com o empreendedorismo. Martinelli (1994) aponta que a definição schumpeteriana de inovação pode ser considerada como sendo a introdução de novas combinações de fatores de produção que, quando eficazmente combinados, alteram, substancialmente, o equilíbrio estático do fluxo circular econômico elevando-o a um patamar inteiramente novo. É interessante apontar que, para Schumpeter (1982) estas novas combinações poderiam abarcar cinco casos específicos: (1) introdução de um novo bem ou de uma nova qualidade de um bem; (2) introdução de um novo método de produção; (3) abertura de um novo mercado; (4) conquista de uma nova fonte de oferta de matérias-primas ou de bens semimanufaturados; e (5) estabelecimento de uma nova organização de qualquer indústria.

Este papel inovativo seria, para Schumpeter (1997), uma função fortemente associada à figura do empreendedor. Tal função, que não implicaria no pré-requisito da propriedade, na assunção de riscos ou no pertencimento a organizações privadas, elevaria a categoria do empreendedor a um patamar extremamente 
importante na teoria econômica em geral e nas abordagens do desenvolvimento econômico de determinadas sociedades em particular.

Schumpeter (1997) afirma, no entanto, que as novas combinações acima descritas não são, necessariamente, efetuadas pelas mesmas pessoas (ou organizações) que controlam o processo produtivo ou comercial atual. Ao contrário, estas novas combinações nascem e são corporificadas por empresas novas que iniciam suas atividades ao lado das antigas. Corroborando tal afirmativa, Drucker (1987, p.29) afirma que "[...] os empreendedores constituem a minoria dentre as pequenas empresas. Eles criam algo novo, algo diferente; eles mudam ou transformam valores". Tal realidade, que tem impactos consideráveis na conformação da estratificação social das sociedades em questão, cria uma nova camada social de empreendedores que passam a servir, inclusive, como modelos de influência para o restante da comunidade.

De acordo com Leite e Melo (2008) e Martinelli (1994), este posicionamento do empreendedor, na contemporaneidade, como uma espécie de "exemplo a ser seguido e copiado" tem como objetivo a transformação de sua experiência individual em experiência coletiva, contribuindo, significativamente, para a (re)produção do habitus coletivo. Em outros termos, busca-se, com essa concepção, contribuir significativamente, para a reprodução do comportamento empreendedor do indivíduo para um comportamento empreendedor societal. Entretanto, outros aspectos sociopolíticos influenciam a atividade empreendedora. De acordo com Baker, Gedajlovic e Lubatkin (2005), o contexto institucional e as estruturas culturais influenciam fortemente as características das oportunidades e os indivíduos que as descobrem, avaliam e exploram.

O componente cultural é tônica constante, aliás, em diversos estudos sobre empreendedorismo (THORTON, 1999; BAKER; GEDAJLOVIC; LUBATKIN, 2005; BEGLEY; TAN, 2001; SILVA; GOMES; CORREIA, 2009). Cumpre destacar, inicialmente, que tais abordagens encontram amparo teórico significativo nos trabalhos de Max Weber. De acordo com Martinelli (1994), Weber contribui, sobremaneira, com seus estudos acerca da influência dos fatores culturais (principalmente do ethos religioso) sobre a dinâmica da atividade econômica. Weber

ENOQUE, A. G.; BORGES, A. F. O espaço do domicílio como lócus da atividade empreendedora: um estudo sobre os empregadores domiciliares no Brasil contemporâneo.

Revista de Empreendedorismo e Gestão de Pequenas Empresas, v. 3, n.1, p. 105-128, 2014. 
(2001) analisou os fenômenos do lucro e do trabalho assalariado sobre a perspectiva cultural do contexto do protestantismo americano. Segundo Martinelli (1994), o capitalista empreendedor weberiano é relativamente distinto dos seus predecessores, caracterizando-se pela busca do ganho econômico, tolerância ao risco e a subordinação do consumo sobre a acumulação.

A partir dessas concepções clássicas sobre 0 fenômeno do empreendedorismo, abriu-se espaço para a exploração científica do campo do empreendedorismo, sobretudo nas áreas de Administração e Economia. A pesquisa sobre empreendedorismo tem sido explorada através de diferentes perspectivas, caracterizando um quadro de análise multifacetado. A pluralidade do campo pode ser observada a partir da diversidade de pesquisas, trabalhos científicos, periódicos e eventos especializados existentes (BUSENITZ et al., 2003; IRELAND; WEBB, 2007; SHEPHERD, 2011).

Com base na evolução do campo e no avanço do conhecimento existente sobre a temática, tem-se uma definição contemporânea de empreendedorismo. Para Carlsson et al. (2013), o domínio do empreendedorismo consiste em uma função econômica desempenhada por indivíduos - empreendedores - que agem de forma independente ou no âmbito interno de organizações, percebendo e criando novas oportunidades de negócio e introduzindo suas ideias no mercado, sob incerteza, tomando decisões sobre localização, design de produtos, utilização de recursos, instituições e sistemas de recompensa. A atividade empreendedora e os negócios empreendedores são influenciados pelo ambiente econômico e contribuem, em última instância, para o crescimento econômico e para o bem-estar humano (CARLSSON et al., 2013).

Para Shane e Venkataraman (2000), a temática do empreendedorismo é que o mesmo abarca duas dimensões distintas, porém, complementares: (1) a presença de oportunidades lucrativas; e (2) a presença de indivíduos dispostos a empreender. Para uma melhor compreensão destas dimensões, os autores delimitam dois pressupostos básicos. O primeiro pressuposto implícito na abordagem de Shane e Venkataraman (2000) consiste na negação da abordagem do equilíbrio presente nas análises econômicas e da psicologia social. De acordo

ENOQUE, A. G.; BORGES, A. F. O espaço do domicílio como lócus da atividade empreendedora: um estudo sobre os empregadores domiciliares no Brasil contemporâneo.

Revista de Empreendedorismo e Gestão de Pequenas Empresas, v. 3, n.1, p. 105-128, 2014. 
com esta abordagem, as oportunidades de negócios seriam randomicamente distribuídas através da população e todos os indivíduos, sem exceção, teriam chance de alcançá-las. Um segundo pressuposto básico importante presente na abordagem de Shane e Venkataraman (2000) é o de que a atividade empreendedora não requer, mas pode incluir, a criação de novas empresas.

Retornando à primeira dimensão do modelo conceitual proposto por Shane e Venkataraman (2000), qual seja, a presença de oportunidades lucrativas, algumas considerações devem ser efetuadas. Para os autores, somente haveria empreendedorismo na medida em que existissem oportunidades empreendedoras. De acordo com Shane e Venkataraman (2000), oportunidades empreendedoras poderiam ser conceituadas como aquelas situações nas quais novos produtos, serviços, matérias-primas e métodos de produção poderiam ser introduzidos ou vendidos a um preço superior aos custos de produção.

Não obstante, Shane e Venkataraman (2000) consideram que a existência por si só de oportunidades não seria suficiente para explicar, totalmente, o fenômeno da atividade empreendedora. O processo de descoberta envolveria a posse de informações anteriores para identificar as oportunidades. É importante destacar, neste ponto e conforme destacam os próprios autores, que estas informações não são largamente distribuídas ao longo da população. Na verdade, elas são reflexo do contorno da estrutura da desigualdade (educacional, por exemplo) em determinada sociedade. É dentro desta perspectiva que Baker, Gedajlovic e Lubatkin (2005) buscam inserir a perspectiva sociológica da estratificação social como um elemento importante na compreensão do processo de descoberta da atividade empreendedora nos diversos países.

Ainda de acordo com Shane e Venkataraman (2000), a avaliação da oportunidade (processo posterior a descoberta), contaria com uma forte contribuição das propriedades cognitivas do indivíduo. Para os autores, mesmo aqueles indivíduos com posse de conhecimentos anteriores (experiência ou proximidade com centros de pesquisa, por exemplo) para identificar as oportunidades de negócio necessitariam de uma habilidade interna para "ver" tais oportunidades. Assim, o processo de exploração da oportunidade seria, também, fortemente influenciado por

ENOQUE, A. G.; BORGES, A. F. O espaço do domicílio como lócus da atividade empreendedora: um estudo sobre os empregadores domiciliares no Brasil contemporâneo.

Revista de Empreendedorismo e Gestão de Pequenas Empresas, v. 3, n.1, p. 105-128, 2014. 
características individuais. Neste sentido, os autores apontam que a decisão de explorar determinada oportunidade estaria associada, por exemplo, a diferenças do nível de otimismo. Ou seja, indivíduos que exploram oportunidades tenderiam a perceber mais chances de sucesso do que outras. É interessante destacar, ainda, que a decisão de explorar determinada oportunidade possui uma dimensão bem mais objetiva. Neste sentido, a inexistência de recursos financeiros para viabilizar o negócio poderia ser considerada uma forte barreira ao processo empreendedor (SHANE; VENKATARAMAN, 2000).

A partir da perspectiva exposta acima, é possível verificar que a natureza da atividade empreendedora pode derivar, também, das motivações para a ação individual. Essas motivações dão origem a diferentes formas de empreendedorismo, como o empreendedorismo por oportunidade e o empreendedorismo por necessidade (RUPPENTHAL; CIMADON, 2012), ou ainda, empreendedorismo voluntário e empreendedorismo involuntário (FILION, 1999). A segunda categoria, empreendedorismo por necessidade ou involuntário, é composta por indivíduos recém-formados ou pessoas demitidas após o fechamento ou reestruturação de empresas. A primeira categoria (voluntários), ao contrário, seria composta por aqueles indivíduos que optam pela atividade empreendedora como uma alternativa de negócio e teria foco na dimensão da inovação. De acordo com dados do GEM (2009), a razão entre empreendedores por necessidade e empreendedores por oportunidade é da ordem de dois para um para a realidade brasileira, e a relevância destes empreendedores por necessidade no Brasil é destacada por Ruppenthal e Cimadon (2012).

Sendo assim, torna-se relevante lançar luzes sobre a realidade de indivíduos empreendedores que executam atividades que podem ser apreendidas no bojo do empreendedorismo por necessidade. Torna-se igualmente interessante compreender a realidade vivenciada por um tipo específico de empreendedor, o qual utiliza de seu espaço domiciliar para desempenhar atividades empresariais.

ENOQUE, A. G.; BORGES, A. F. O espaço do domicílio como lócus da atividade empreendedora: um estudo sobre os empregadores domiciliares no Brasil contemporâneo. Revista de Empreendedorismo e Gestão de Pequenas Empresas, v. 3, n.1, p. 105-128, 2014. 
Procedimentos Metodológicos

As análises efetuadas no corpo deste trabalho foram feitas a partir de dados secundários provenientes da Pesquisa Nacional por Amostra de Domicílios (PNAD) entre os anos de 1992 e 2007. Tal banco de dados, amplamente utilizado por pesquisadores nacionais e internacionais e cuja periodicidade obedece a critérios anuais (com exceção dos anos abarcados pelo Censo Populacional), investiga diversas características socioeconômicas relacionadas à realidade brasileira. Algumas destas características possuem um caráter permanente nas pesquisas como, por exemplo, aquelas relacionadas às características gerais da população, à educação, ao trabalho, ao rendimento dos entrevistados e, finalmente, a habitação. Outras características, de natureza e periodicidade variável, como, por exemplo, migração, fecundidade, nupcialidade, saúde e nutrição, são abordados por pesquisas suplementares que acompanham o corpo geral do questionário.

Para fins deste trabalho, foram selecionadas as seguintes edições da PNAD: 1992, 1993, 1995, 1996, 1997, 1998, 1999, 2001, 2002, 2003, 2004, 2005, 2006 e 2007. A opção pelos anos acima está relacionada à possibilidade de construção de um panorama histórico-evolutivo e analítico do empregador domiciliar brasileiro pósdécada de 1990. O recorte pós-década de noventa diz respeito, basicamente, ao fato de que tal atividade ressurgiu para a realidade brasileira (fato que ocorreu em outros países em meados da década de oitenta) neste período histórico específico. Neste sentido, este trabalho optou por traçar um panorama histórico-evolutivo que contemplou um período de quinze anos (1992 a 2007). Convêm destacar que, embora existam outras PNAD's mais recentes disponíveis (2008, 2009, 2011 e 2012), este estudo optou por limitar sua análise até o ano de 2007, uma vez que o ano seguinte (2008) apresentou características sócio-econômicas peculiares decorrentes de uma crise mundial e que seus impactos (no próprio ano e nos anos seguintes) poderiam, de alguma forma, afetar a compreensão de características específicas do fenômeno do empregador domiciliar.

No que se refere à categoria "Empregadores Domiciliares", foram selecionados os indivíduos residentes no meio urbano, com idade entre 15 e 65

ENOQUE, A. G.; BORGES, A. F. O espaço do domicílio como lócus da atividade empreendedora: um estudo sobre os empregadores domiciliares no Brasil contemporâneo.

Revista de Empreendedorismo e Gestão de Pequenas Empresas, v. 3, n.1, p. 105-128, 2014. 
anos, que exerciam suas tarefas no espaço do domicílio e classificados enquanto "empregadores" (possuíam empregados), conforme modelo proposto por Enoque (2009). Convêm destacar que a opção pela população economicamente ativa e pelo espaço urbano foram opções metodológicas dos autores e que tais decisões não inviabilizariam, em momento posterior, análises específicas sobre a realidade do meio rural, por exemplo, ou de empregadores com idade posterior a 65 anos.

A partir dos dados levantados a partir das bases, foi feita uma análise descritiva de algumas variáveis que nos apontam características individuais e sóciodemográficas destacadas na literatura como interligadas aos empregadores domiciliares:

- Gênero: variável indicadora (dummy): 1 = masculino e 0 = feminino;

- Raça: variável indicadora (dummy): 1 = branco e 0 = não-branco (Convêm destacar, neste ponto, que as categorias pardo e preto foram agrupadas e nomeadas como não-brancos. No caso dos amarelos e indígenas, os mesmos foram retirados da amostra. Por fim, a categoria branco foi mantida para fins de análise);

- Escolaridade: número de anos de escolaridade completados;

- Idade: número de anos de idade completados;

- Experiência Profissional: idade atual do respondente menos a idade em que começou a trabalhar;

- Não-migrante: nasceu no município de moradia atual;

- Migrante intra-estadual: mora em município no mesmo Estado da Federação onde nasceu (Convêm destacar que o município de moradia, embora esteja no mesmo Estado da Federação, não é o mesmo do nascimento do respondente);

- Migrante inter-estadual: mora em um município de um Estado da Federação diferente daquele onde nasceu;

- Horas trabalhadas por semana: número de horas trabalhadas por semana;

- Horas dedicadas aos afazeres domésticas: número de horas dedicadas aos afazeres domésticos por semana;

- Filhos: variável indicadora (dummy): $1=$ tem filhos menores de 14 anos e $0=$ não tem filhos menores de 14 anos;

ENOQUE, A. G.; BORGES, A. F. O espaço do domicílio como lócus da atividade empreendedora: um estudo sobre os empregadores domiciliares no Brasil contemporâneo. Revista de Empreendedorismo e Gestão de Pequenas Empresas, v. 3, n.1, p. 105-128, 2014. 
- Tempo no trabalho: número de anos em que o respondente permaneceu na atividade;

- Rendimento salarial: em salários-mínimos (Convêm destacar que as análises sobre esta variável foram feitas a partir de 1995);

- Participação em Sindicatos (dummy), 1 = participa de sindicatos e 0 = não participa de sindicatos;

$\mathrm{Na}$ confecção da análise foram feitas, ainda, comparações com outras duas categorias importantes de análise ("empregadores em atividade não-domiciliar" e "trabalhadores domiciliares"). No que diz respeito à primeira categoria, a mesma pode ser entendida como compreendendo os indivíduos com idade entre 15 e 65 anos, residentes no meio urbano, classificados como empregadores (possuíam empregados) e que exerciam suas atividades fora do espaço do domicílio. Em relação a segunda categoria ("trabalhadores domiciliares"), a mesma pode ser entendida como sendo composta por trabalhadores (exercem algum tipo de atividade produtiva e não contam com a colaboração de empregados), com idade entre 15 e 65 anos, residentes no meio urbano e que desenvolvem suas tarefas dentro do espaço do domicílio.

Convêm destacar, por fim, que as análises que serão apresentadas na próxima seção foram realizadas utilizando estatística descritiva simples tendo como principal instrumento o pacote estatístico SPSS.

\section{Atividade Empreendedora e o Empregador Domiciliar: Análise da Realidade Brasileira}

Um primeiro aspecto a ser destacado diz respeito ao crescimento numérico dos indivíduos classificados como "empregadores domiciliares" para a realidade brasileira no período compreendido entre 1992 e 2007. Com base nos dados analisados, o crescimento médio, para o período analisado, de tal categoria foi da ordem de 7,67\%. Para fins de comparação, o crescimento dos empregadores alocados em atividades não-domiciliares girou em torno de 2,92\%. É importante destacar, no entanto, que a participação dos empregadores ocupados em atividades 
não-domiciliares (fora do espaço do domicílio) no total daqueles que empregam mão-de-obra é, em média, de 96,54 \%. Ao contrário, a participação dos "empregadores domiciliares", ou seja, empregadores que executam atividades dentro do espaço do domicílio é de, aproximadamente, 3,46 \%. Destaca-se, ainda, que a média de participação dos "empregadores domiciliares" no total da mão-deobra brasileira, no período analisado, é de 0,16\%.

No que se refere à variável gênero, observa-se que há uma maior participação de homens na composição dos indivíduos classificados como "empregadores domiciliares" (média de 52,04 \% para o período analisado). Nota-se, no entanto, que os anos de 1993, 1995, 2001 e 2004 são exceções, com uma maior participação feminina. Tal realidade é interessante na medida em que se apresenta como um contraponto evidente a literatura sobre trabalho domiciliar no Brasil e no mundo, a qual apresenta fortes contornos de gênero. É importante destacar que, neste último tipo de atividade, há uma clara participação de um contingente feminino (FIGURA 1).

Figura 1: Participação Feminina (“Empregador Domiciliar” $x$ "Empregador NãoDomiciliar")

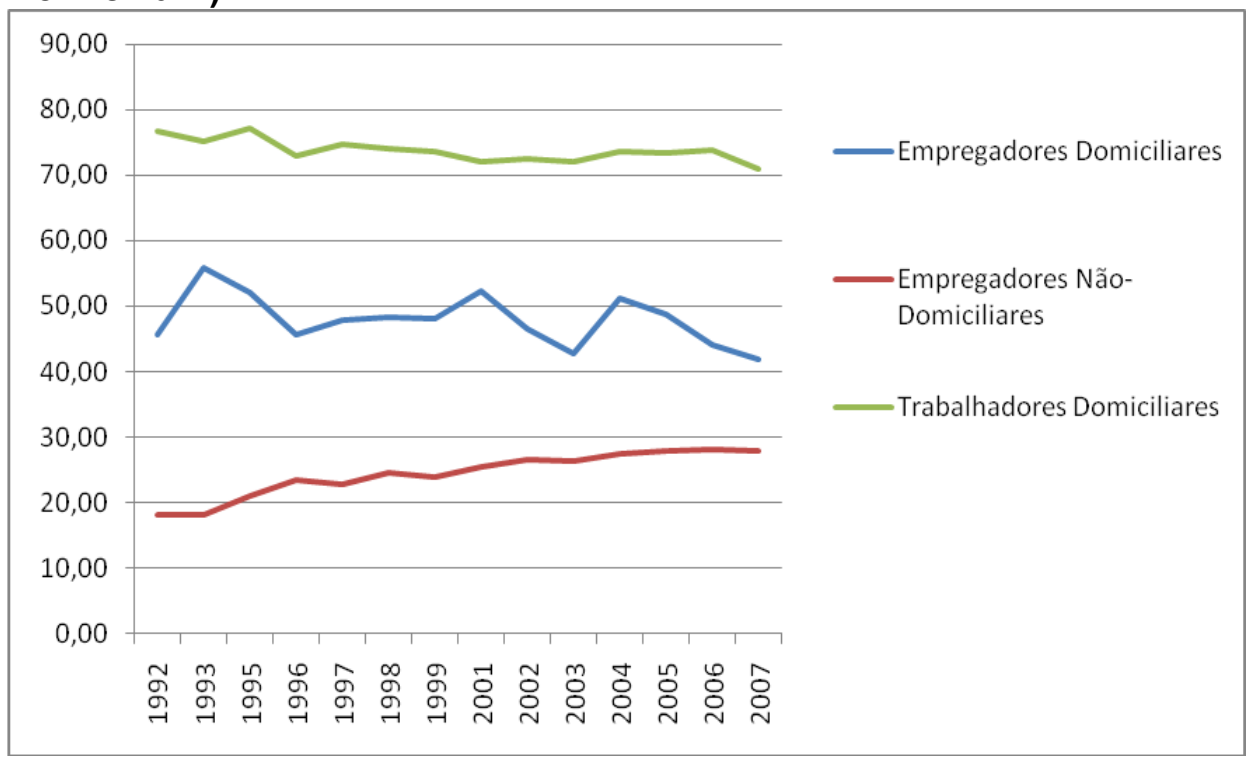

Fonte: Pesquisa Nacional por Amostra de Domicílios (PNAD).

Outro ponto interessante é que, no comparativo entre empregadores de fora e de dentro do domicílio ("Empregadores Domiciliares"), há uma maior participação feminina para o segundo. Tal realidade pode estar relacionada à necessidade das mulheres de conciliar ENOQUE, A. G.; BORGES, A. F. O espaço do domicílio como lócus da atividade empreendedora: um estudo sobre os empregadores domiciliares no Brasil contemporâneo. Revista de Empreendedorismo e Gestão de Pequenas Empresas, v. 3, n.1, p. 105-128, 2014. 
atividades de cunho puramente doméstico com outras atividades voltadas para o mercado, ainda que as mesmas sejam categorizadas como empregadoras de mão-de-obra. Ao observarmos os empregadores em atividade não-domiciliar, notamos que, embora crescente, a participação feminina gira em torno de 20 a $30 \%$ para o período analisado. Nota-se, neste sentido, que parece haver uma segmentação espacial (dentro/fora do domicílio) no mercado de trabalho brasileiro que tem fortes contornos de gênero.

Em relação à variável raça, podemos observar que há uma maior participação da categoria "brancos" no total dos indivíduos classificados como "empregadores domiciliares" (média de 60,22 \%). Ressalta-se, no entanto, que, conforme pode ser observado no gráfico abaixo, existe uma tendência de convergência entre as duas categorias ("brancos" e "nãobrancos") ao longo do período analisado. É importante destacar que tal realidade aproximase, sobremaneira, daquela apresentada sobre a dinâmica racial na sociedade brasileira (FIGURA 2).

Figura 2: Raça x "Empregadores Domiciliares"

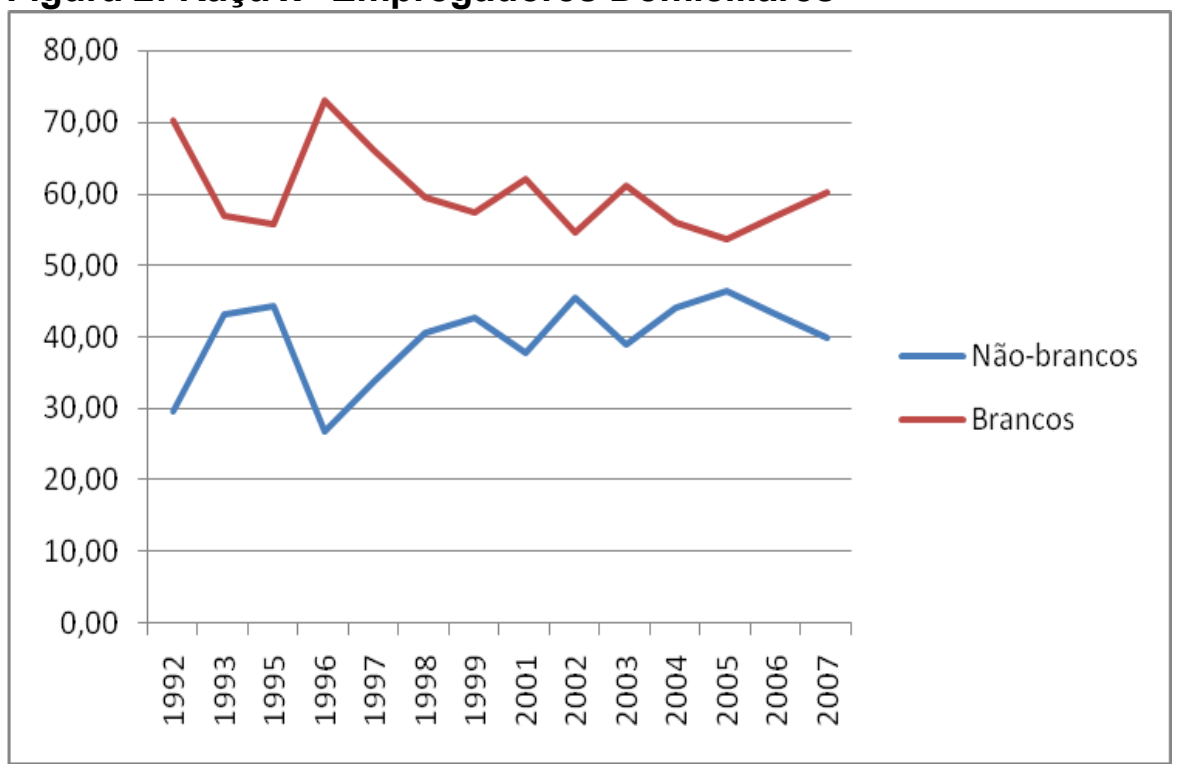

Fonte: Pesquisa Nacional por Amostra de Domicílios (PNAD).

Observa-se que o grupo que apresenta o maior patamar de participação de indivíduos "brancos" é o de empregadores em atividade não-domiciliar com uma média para o período analisado de $73,75 \%$. Em seguida, embora com uma redução de 10 pontos percentuais entre os anos de 1992 e 2007, encontra-se o grupo dos empregadores em atividade domiciliar ("empregadores domiciliares") com uma média de participação de "brancos" da ordem de 60,22 \%, e a categoria "trabalhadores domiciliares" (47,12 \%). Tal

ENOQUE, A. G.; BORGES, A. F. O espaço do domicílio como lócus da atividade empreendedora: um estudo sobre os empregadores domiciliares no Brasil contemporâneo. Revista de Empreendedorismo e Gestão de Pequenas Empresas, v. 3, n.1, p. 105-128, 2014. 
realidade parece demonstrar, da mesma forma apresentada em relação à variável gênero, uma relativa segmentação espacial em termos raciais (FIGURA 3).

Figura 3: Participação raça "branca"

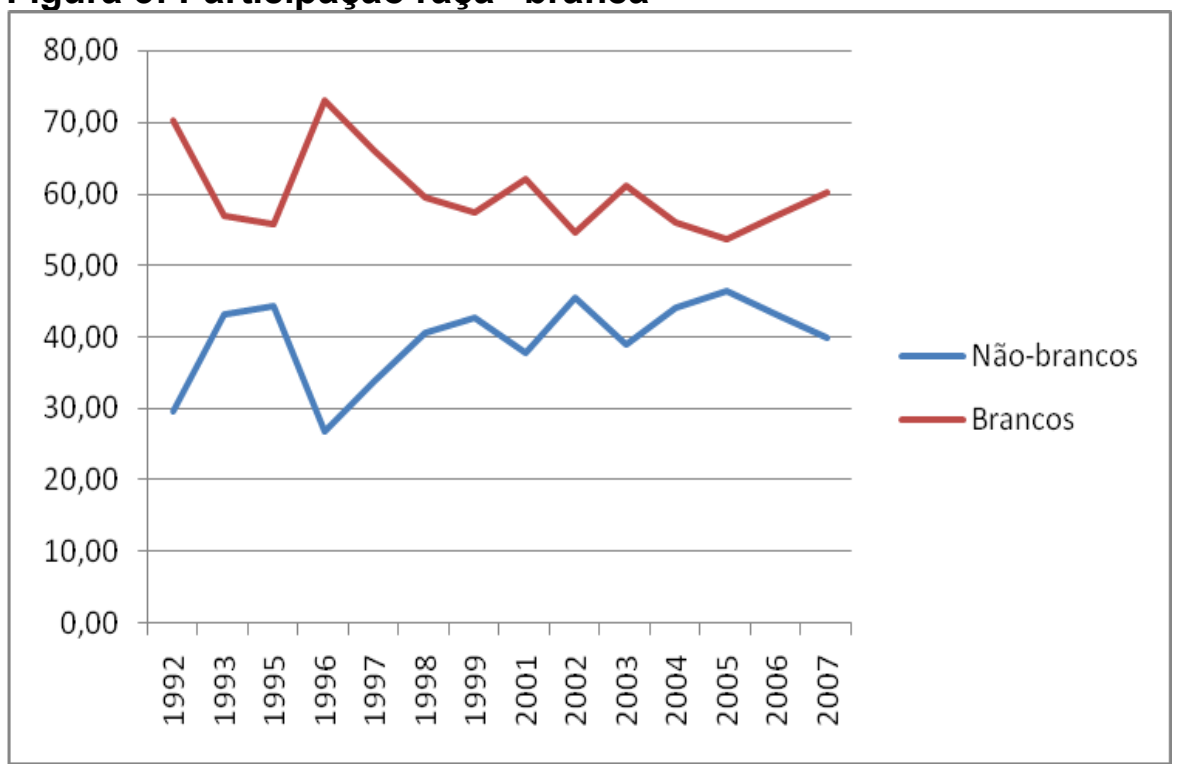

Fonte: Pesquisa Nacional por Amostra de Domicílios (PNAD).

Em relação ao status migratório dos indivíduos classificados como "empregadores domiciliares", nota-se que há uma maior participação de "não-migrantes" (média, para o período analisado, de cerca de 36,49 \%) e "migrantes intra-estaduais" (36,86 \%). A participação dos "migrantes inter-estaduais" encontra-se em um patamar inferior, atingindo, para o ano de 2007, o valor de 21,99\%.

No que se refere à variável escolaridade, pode-se observar uma tendência de crescimento da mesma nas três categorias analisadas (empregadores em atividade domiciliar - "empregadores domiciliares", empregadores em atividade não-domiciliar e "trabalhadores domiciliares"). Observa-se, no entanto, que a maior taxa média de crescimento para o período analisado (1992 a 2007) foi dos indivíduos classificados como "trabalhadores domiciliares" (cerca de 2,08 \%). Em seguida, encontram-se: "empregadores em atividade não-domiciliar" (1,13\%) e "empregadores domiciliares" $(0,72 \%)$.

Há que se destacar, no entanto, que a maior média de escolaridade, dentre as três categorias analisadas e, conforme pode ser observado no gráfico abaixo, é a dos "empregadores em atividade não-domiciliar" (média de 10,72 anos de estudo). Em segundo lugar, apresenta-se os "empregadores domiciliares" com uma média de escolaridade, para o período analisado, de 9,49 anos de estudo (FIGURA 4).

ENOQUE, A. G.; BORGES, A. F. O espaço do domicílio como lócus da atividade empreendedora: um estudo sobre os empregadores domiciliares no Brasil contemporâneo. Revista de Empreendedorismo e Gestão de Pequenas Empresas, v. 3, n.1, p. 105-128, 2014. 


\section{Figura 4: Anos de escolaridade}

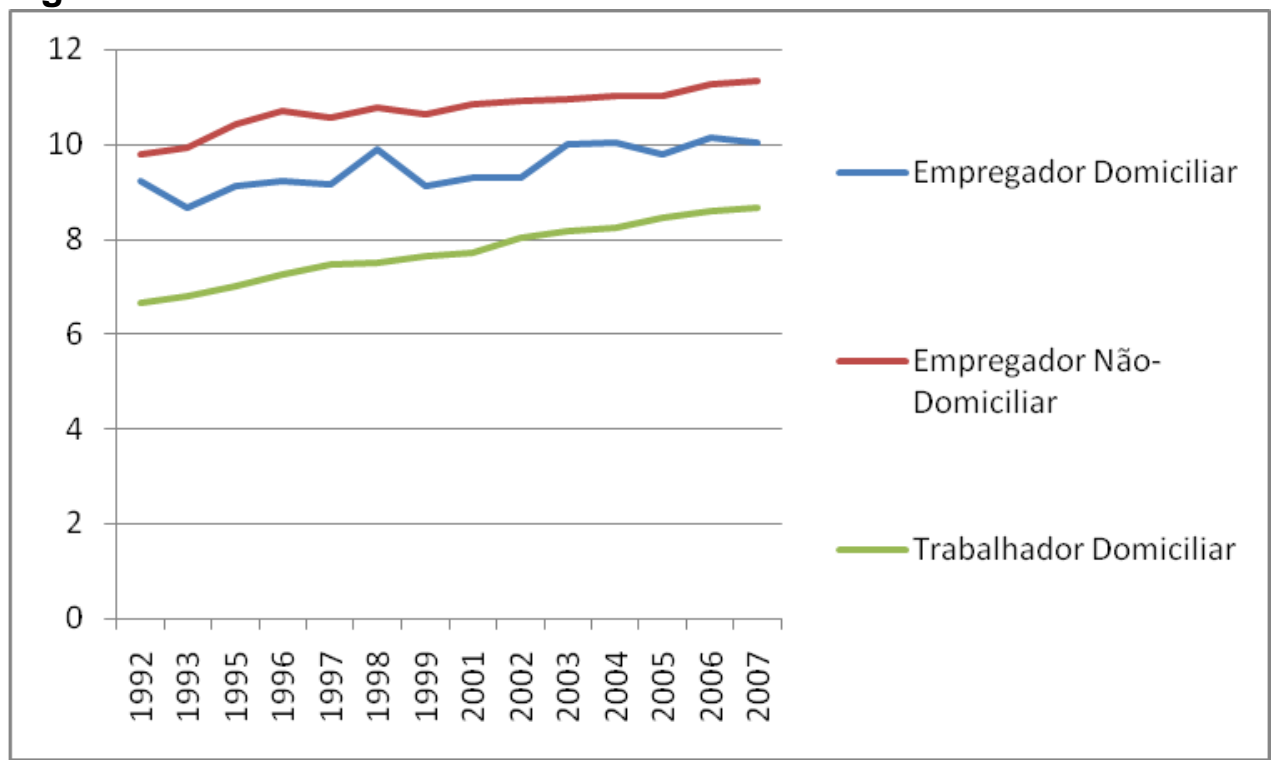

Fonte: Pesquisa Nacional por Amostra de Domicílios (PNAD).

Em relação à faixa etária dos indivíduos analisados, observa-se que aqueles classificados como empregadores (com atividades dentro e fora do domicílio) tendem a possuir uma média de idade superior aos "trabalhadores domiciliares". É importante destacar, no entanto, o comportamento irregular, porém crescente, da categoria "empregadores domiciliares" que apresentou um desvio-padrão médio da ordem de 0,46 anos. Destaca-se, ainda, que a média de idade para tal categoria apresentou um substancial crescimento entre o ano de 1992 e 2007 (8,26\%).

É importante pontuar, ainda, que a realidade apresentada acima impacta, sobremaneira, a variável experiência profissional. Conforme pode ser observado no gráfico abaixo, as maiores médias de experiência profissional estão relacionadas aos indivíduos classificados como empregadores (dentro e fora do domicílio). Em um patamar inferior, encontram-se os indivíduos da categoria "trabalhadores domiciliares" com uma média de experiência, para o período analisado, da ordem de 25,15 anos (FIGURA 5).

ENOQUE, A. G.; BORGES, A. F. O espaço do domicílio como lócus da atividade empreendedora: um estudo sobre os empregadores domiciliares no Brasil contemporâneo. Revista de Empreendedorismo e Gestão de Pequenas Empresas, v. 3, n.1, p. 105-128, 2014. 


\section{Figura 5: Experiência Profissional}

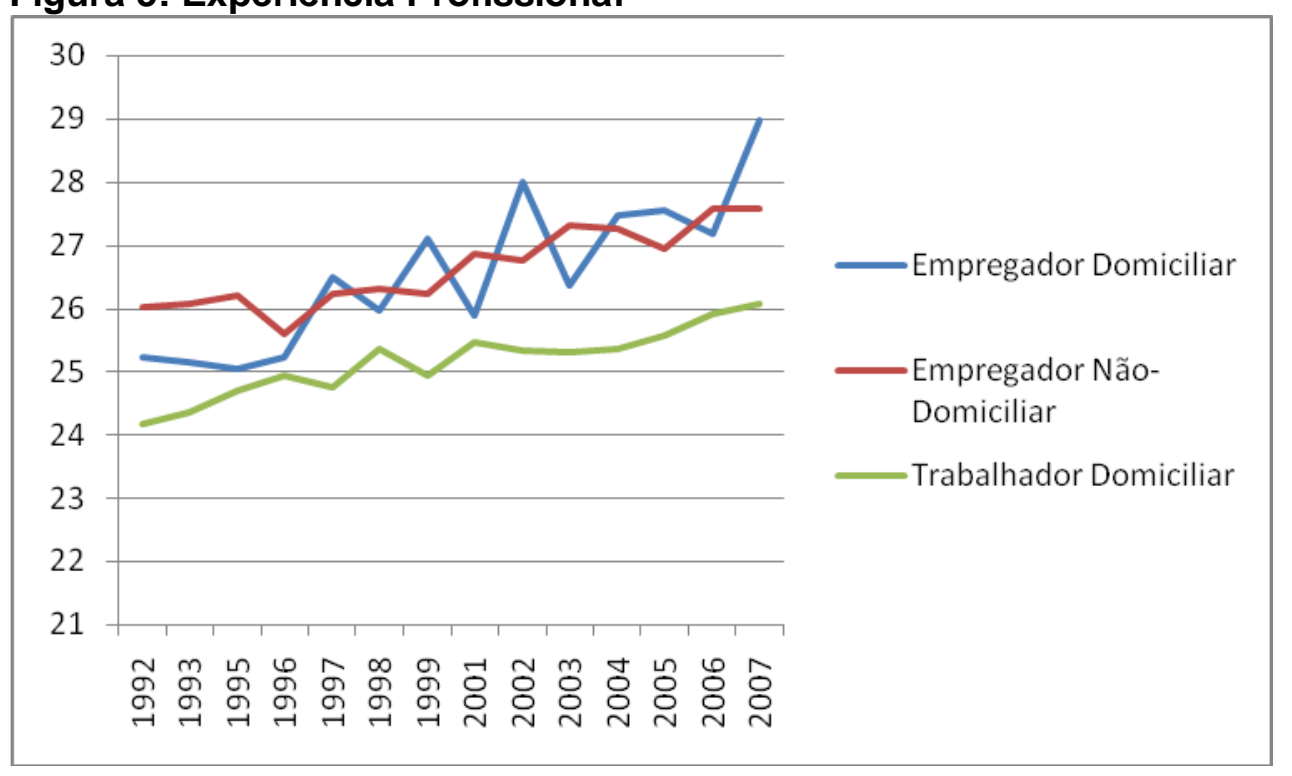

Fonte: Pesquisa Nacional por Amostra de Domicílios (PNAD).

No comparativo da média do número de horas trabalhadas por semana entre as três categorias, observa-se que os maiores valores podem ser alocados aos indivíduos classificados como empregadores (dentro e fora do domicílio). Enquanto o grupo dos empregadores domiciliares apresenta uma média de horas trabalhadas da ordem de 48,17, o segundo grupo, ou seja, daqueles empregadores alocados em atividade não-domiciliar, trabalham, em média, 49,67 horas. Nota-se que tais categorias apresentam valores bastante superiores aos dos indivíduos classificados como "trabalhadores domiciliares" (média de 34,36 horas por semana).

Ressalta-se que o número reduzido de horas trabalhadas por semana relacionado aos "trabalhadores domiciliares" pode estar, de alguma forma, relacionado à necessidade de dispêndio de tempo dos mesmos em atividades de cunho doméstico. Como pode ser observado no gráfico abaixo, o número de horas gasto pelos mesmos (25,47 horas) encontra-se em patamar bastante superior aos indivíduos classificados como empregador: "empregador domiciliar" (17,42 horas) e "empregador em atividade não-domiciliar" (11,85 anos) (FIGURA 6).

ENOQUE, A. G.; BORGES, A. F. O espaço do domicílio como lócus da atividade empreendedora: um estudo sobre os empregadores domiciliares no Brasil contemporâneo. Revista de Empreendedorismo e Gestão de Pequenas Empresas, v. 3, n.1, p. 105-128, 2014. 


\section{Figura 6: Horas dedicadas aos afazeres domésticos}

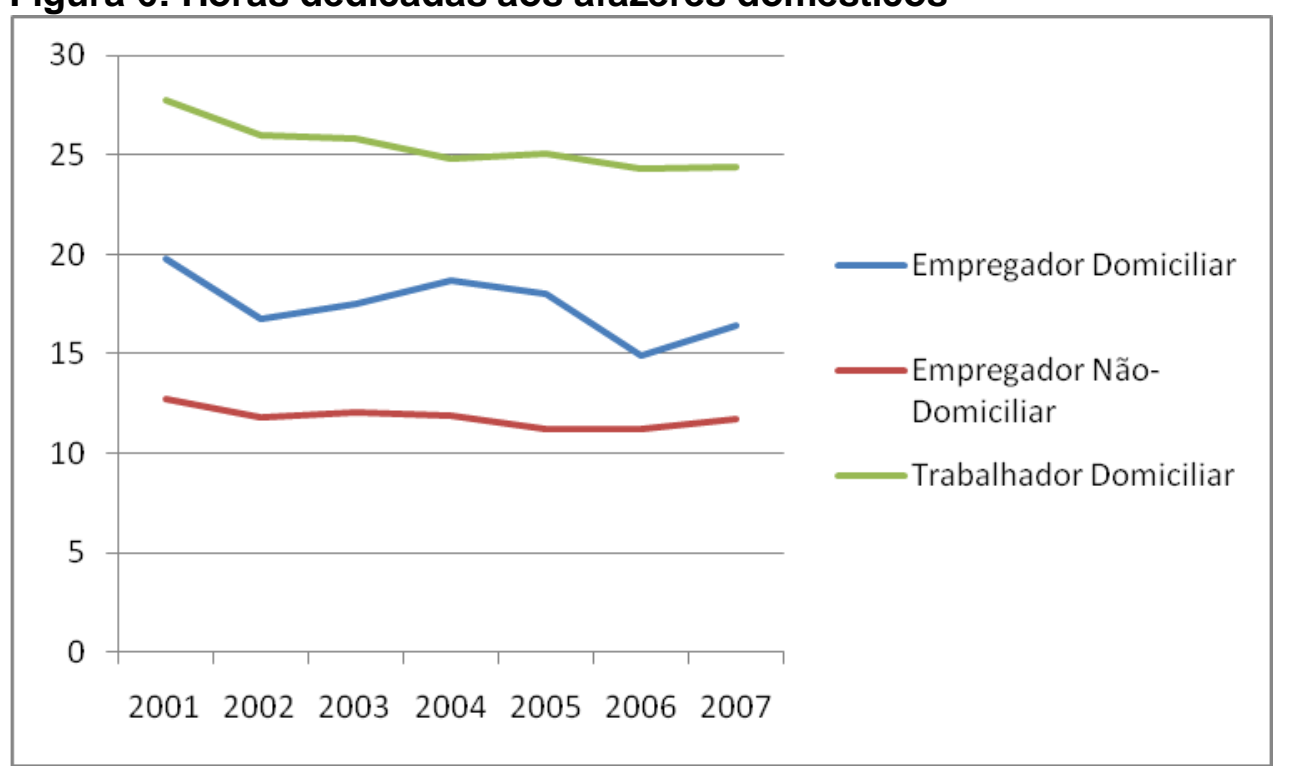

Fonte: Pesquisa Nacional por Amostra de Domicílios (PNAD).

Comportamento semelhante pode ser observado em relação à participação de indivíduos que afirmam executar afazeres domésticos (convêm destacar que a mudança no período de análise deve-se, fundamentalmente, a inexistência da pergunta sobre afazeres domésticos no corpo das PNAD's da década de noventa). A participação de indivíduos que cuidam de afazeres domésticos é superior no grupo "trabalhadores domiciliares" (média de $85,75 \%$ ). No que tange à composição familiar, observamos que há um declínio, para todas as duas categorias analisadas, do percentual de famílias com filhos menores de 14 anos. Enquanto para o ano de 1992, os percentuais giravam em torno de $59 \%$, em 2007, os valores eram de $34,71 \%$ para os empregadores domiciliares e $42,62 \%$ para os nãodomiciliares.

Em relação ao tempo de permanência em anos na atividade, nota-se que os indivíduos classificados como "empregadores em atividade não-domiciliar" encontram-se em um patamar superior. Com uma tendência crescente a partir do ano de 1996 e uma média de crescimento para o período da ordem de 0,84 \%, a média de permanência na atividade, no período compreendido entre 1992 e 2007, girou em torno de 9,94 anos. Em um patamar inferior, porém com uma tendência crescente e com uma linha de corte a partir do ano de 2001, os "empregadores domiciliares" apresentaram um crescimento médio da ordem de 2,59 \%, atingindo, em 2007, um tempo de permanência na atividade de 9,37 anos (FIGURA 7).

ENOQUE, A. G.; BORGES, A. F. O espaço do domicílio como lócus da atividade empreendedora: um estudo sobre os empregadores domiciliares no Brasil contemporâneo. Revista de Empreendedorismo e Gestão de Pequenas Empresas, v. 3, n.1, p. 105-128, 2014. 
Figura 7: Número de anos neste trabalho

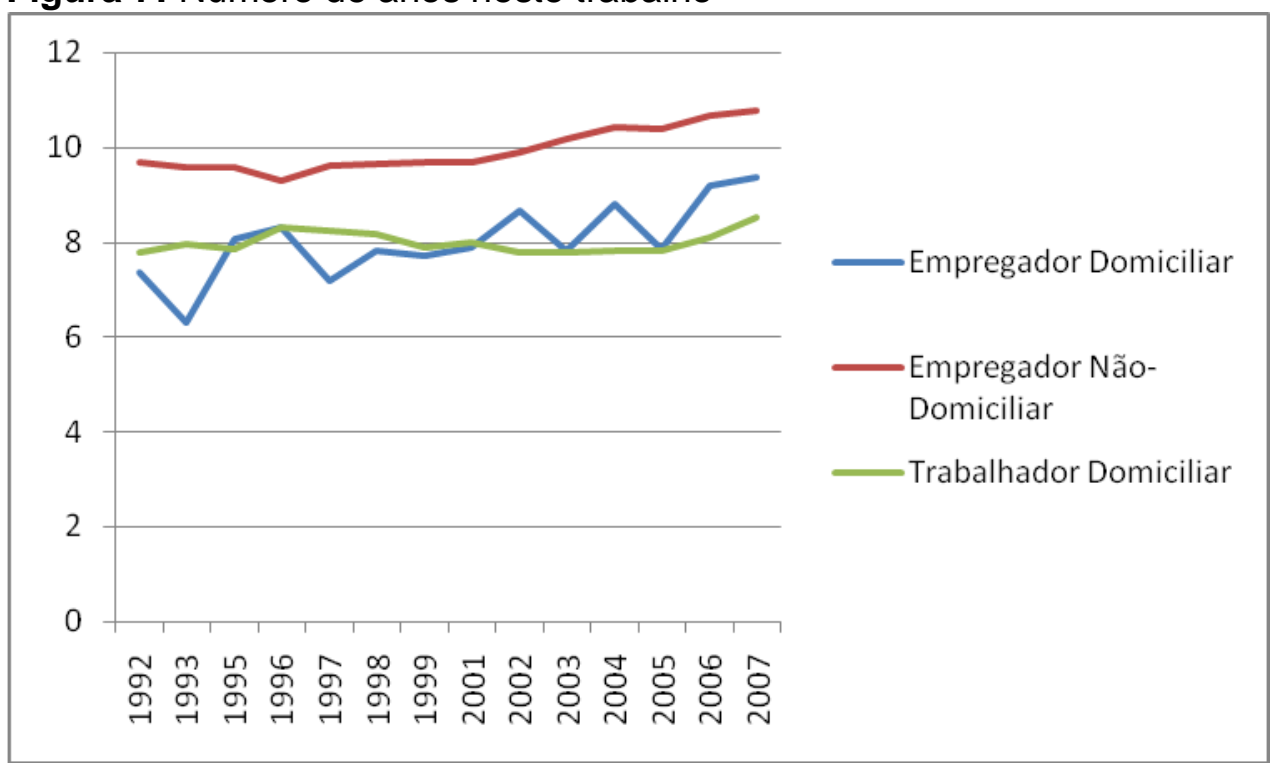

Fonte: Pesquisa Nacional por Amostra de Domicílios (PNAD).

Em relação à questão salarial, podemos observar, através do gráfico abaixo, que há uma tendência de crescimento no valor absoluto dos rendimentos dos trabalhadores nas duas categorias analisadas. Deve-se destacar, no entanto, que o maior patamar salarial é dos "empregadores em atividade não-domiciliar" (média de R\$ 2.250,32). Em segundo lugar, apresenta-se os "empregadores domiciliares" (média de R\$1.267,61) (FIGURA 8).

Figura 8: Evolução dos Rendimentos (em $\mathrm{R} \$$ )

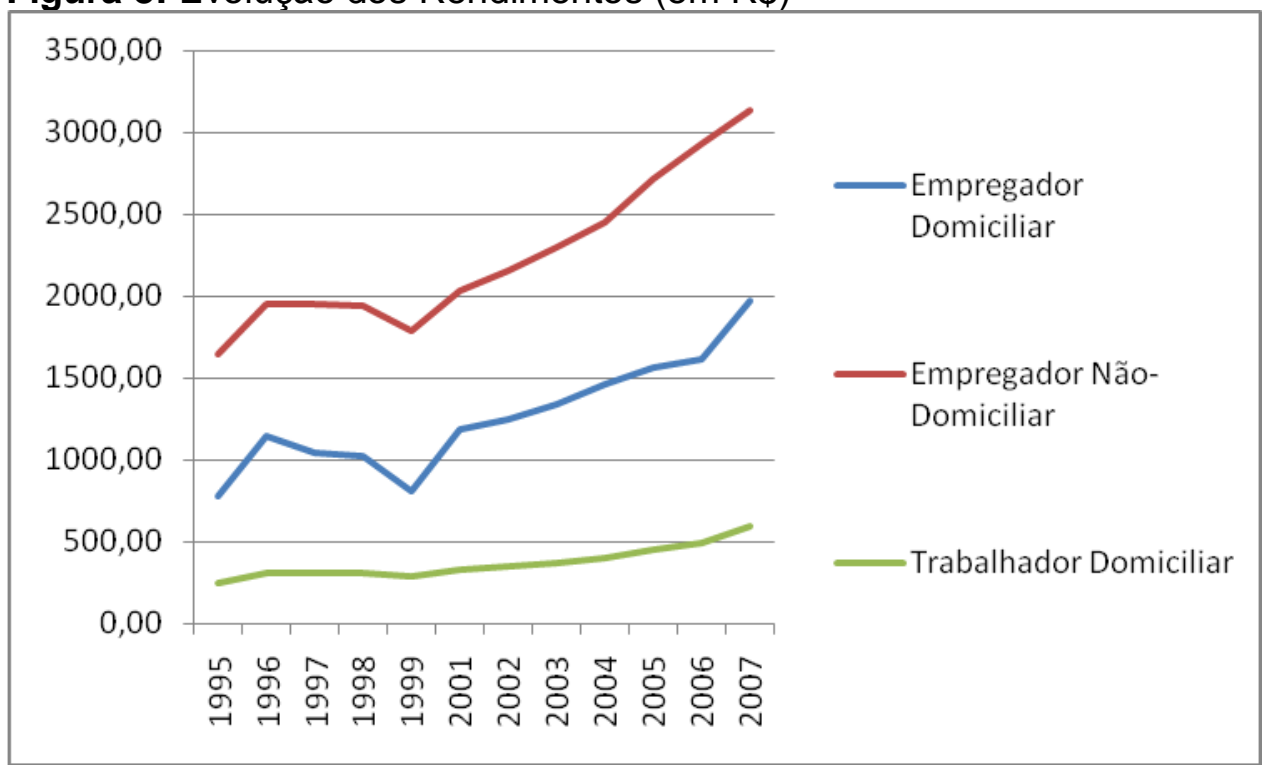

Fonte: Pesquisa Nacional por Amostra de Domicílios (PNAD).

ENOQUE, A. G.; BORGES, A. F. O espaço do domicílio como lócus da atividade empreendedora: um estudo sobre os empregadores domiciliares no Brasil contemporâneo. Revista de Empreendedorismo e Gestão de Pequenas Empresas, v. 3, n.1, p. 105-128, 2014. 
Ao analisarmos, no entanto, o valor dos rendimentos de acordo com a relação entre o número absoluto do mesmo e o salário-mínimo dos anos pesquisados, notamos que a tendência é de declínio. Em 1996, cujo valor do salário-mínimo correspondia a $R \$ 112,00$, os "empregadores não-domiciliares" recebiam, em média, 17,46 salários-mínimos. Para a mesma categoria, no ano de 2007, a relação era da ordem de 8,25 salários-mínimos. Realidade semelhante pode ser observada para a categoria "empregador domiciliar". No ano de 1996, o valor dos rendimentos girava em torno de 10,25 salários-mínimos. Em 2007, o valor dos rendimentos encontrou seu menor patamar (5,19 salários-mínimos).

No comparativo entre as três categorias, observa-se que a maior taxa de participação em sindicatos é, exatamente, dos indivíduos classificados como "empregadores não-domiciliares" (média de 19,32 \%). Há que se destacar, no entanto, que a tendência desta participação é decrescente ao longo do período analisado, indicando, potencialmente, um enfraquecimento do poder sindical (mesmo patronal) na realidade brasileira das décadas de noventa e atual (FIGURA 9).

Figura 9: Participação em Sindicatos

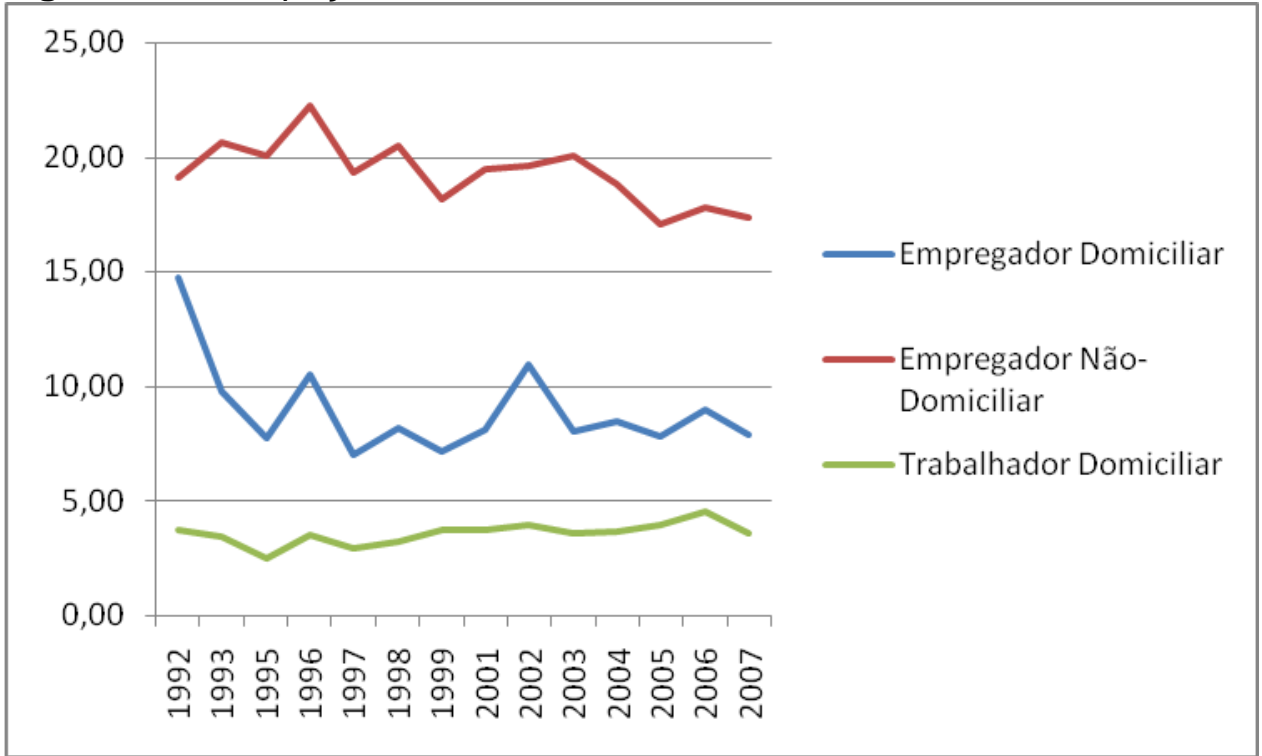

Fonte: Pesquisa Nacional por Amostra de Domicílios (PNAD).

Realidade semelhante, porém em um patamar de participação inferior, pode ser observada para os indivíduos classificados como "empregadores domiciliares". Partindo de uma taxa de participação da ordem de $14,71 \%$ no ano de 1992, esta categoria apresentou, em 2007, valor de 7,9\%.

ENOQUE, A. G.; BORGES, A. F. O espaço do domicílio como lócus da atividade empreendedora: um estudo sobre os empregadores domiciliares no Brasil contemporâneo. Revista de Empreendedorismo e Gestão de Pequenas Empresas, v. 3, n.1, p. 105-128, 2014. 


\section{Considerações Finais}

Tendo em vista a relevância de estudos que buscam compreender a dinâmica da atividade empreedendora locada no espaço do domicílio, o presente trabalho teve como objetivo principal traçar um perfil dos empregadores domiciliares no Brasil contemporâneo. Entendidos como aqueles indivíduos com idade entre 15 e 65 anos, residentes no meio urbano, que exercem atividades produtivas no espaço do domicílio e que contam com a ajuda de empregados, os empregadores domiciliares foram comparados com outras duas categorias de referência ("empregadores em atividade não-domiciliar" e "trabalhador domiciliar").

Tal comparação, instrumentalizada por uma série histórica retirada das Pesquisas Nacionais por Amostra de Domicílios (PNAD's) e analisada através da utilização de software estatístico (SPSS), possibilitou uma melhor compreensão da natureza deste tipo de atividade inserida nas tramas do tecido produtivo brasileiro.

Foi possível, neste sentido, compreender que este tipo de atividade ("empregador domiciliar") apresenta um crescimento numérico evidente no período analisado (cerca de 7,67 \% entre 1992 e 2007). Além disto, apresenta claros contornos de gênero e raça ao ocupar uma mão-de-obra tipicamente masculina (média de 52,04 \% para o período analisado) e branca (60,22 \% dos indivíduos inseridos nesta categoria eram brancos). No que se refere a variável escolaridade, os mesmos apresentaram elevado nível (9,49 anos de estudo) ficando em patamar inferior somente aos empregadores em atividade não-domiciliar (10,72 anos). Notase, neste sentido, que as duas categorias acima mencionadas apresentam um elevado grau de escolaridade no comparativo com o restante da população brasileira. Uma outra questão importante diz respeito a média de trabalho semanal elevada (cerca de 48,17 horas). Tal realidade parece impactar, sobremaneira, o desempenho das atividades domésticas (os empregadores domiciliares contribuem somente com cerca de 17,42 horas semanais). No que tange ao tempo médio de permanência como empregadores domiciliares, o mesmo foi da ordem de 9,37 anos.

Sendo assim, conclui-se que diversos aspectos podem influir sobre as perspectivas de construção e condução de atividades empreendedoras no âmbito

ENOQUE, A. G.; BORGES, A. F. O espaço do domicílio como lócus da atividade empreendedora: um estudo sobre os empregadores domiciliares no Brasil contemporâneo.

Revista de Empreendedorismo e Gestão de Pequenas Empresas, v. 3, n.1, p. 105-128, 2014. 
domiciliar, revelando desafios de interpretação a serem superados no campo do empreendedorismo. Há, evidentemente, que se levar em consideração esta importante categoria, negligenciada nos estudos sobre o empreendedorismo, de modo a associá-la, por exemplo, a questões pertinentes à compreensão do papel e da atuação do microempreendedor e do microempreendedorismo, enquanto agentes potenciais de desenvolvimento econômico e social. Esse tipo de movimento, ao ser realizado, abriria espaço para novas linhas de investigação e estudos futuros sobre esses objetos, promovendo avanços desejáveis e necessários na literatura e no conhecimento científico acerca do fenômeno empreendedor.

\section{Referências}

BAKER, T.; GEDAJLOVIC, E.; LUBATKIN, M. A Framework for Comparing Entrepreneurship Processes Across Nations. Journal of International Business Studies, v. 36, n. 5, p. 490-504, set. 2005.

BEGLEY, T. M.; TAN, W.-L. The Socio-Cultural Environment for Entrepreneurship: A Comparison between East Asian and Anglo-Saxon Countries. Journal of International Business Studies, v. 32, n. 3, 2001.

BUSENITZ, L. W.; WEST III, G. P.; SHEPHERD, D.; NELSON, T.; CHANDLER, G. N.; ZACHARAKIS, A. Entrepreneurship Research in Emergence: past trends and future directions. Journal of Management, Thousand Oaks, v. 29, n. 3, p. 285-308, mai. 2003.

CARLSSON, B.; BRAUNERHJELM, P; MCKELVEY, M.; OLOFSSON, C; PERSSON, L.; YLINENPAA, H. The evolving domain of entrepreneurship research. Small business Economics, v. 41, n.4, p. 913-930, dez. 2013

CORNELIUS, B.; LANDSTRÖM, H.; PERSSON, O. Entrepreneurial studies: the dynamic research front of a developing social science. Entrepreneurship: Theory \& Practice, v. 30, n. 3, p. 375-398, mai. 2006.

DRUCKER, P. F. Inovação e Espírito Empreendedor: Práticas e Princípios. São Paulo: Pioneira, 1987.

ENOQUE, A. G. Por Trás dos Fios Invisíveis: Configurações do Trabalho Domiciliar Urbano no Brasil Contemporâneo. Tese (Doutorado em Ciências Humanas). Universidade Federal de Minas Gerais, Belo Horizonte, 2009.

ENOQUE, A. G.; BORGES, A. F. O espaço do domicílio como lócus da atividade empreendedora: um estudo sobre os empregadores domiciliares no Brasil contemporâneo. Revista de Empreendedorismo e Gestão de Pequenas Empresas, v. 3, n.1, p. 105-128, 2014. 
FILION, L. J. Empreendedorismo: empreendedores e proprietários-gerentes de pequenos negócios. Revista de Administração de Empresas, São Paulo, v. 39, n.4, p. 06-20, abr./jun. 1999b.

GLOBAL ENTREPRENEURSHIP MONITOR (GEM). Curitiba: IBQP, 2009.

GOMES, A. F.; LIMA, J. B.; CAPPELLE, M. C. A. Do Empreendedorismo à Noção de Ações Empreendedoras: Reflexões Teóricas. Revista Alcance, v. 20, n. 2, p. 203220, abr./jun. 2013.

IRELAND, R. D.; WEBB, J. W. A Cross-Disciplinary Exploration of Entrepreneurship Research. Journal of Management, Thousand Oaks, v. 33, n. 6, p. 891-927, dez. 2007.

LEITE, E. S.; MELO, N. M. Uma Nova Noção de Empresário: A Naturalização do "Empreendedor". Revista de Sociologia e Política, v. 16, n. 31, 2008.

MARTINELLI, A. Entrepreneurship and Management. In: SMELSER, N. J.; SWEDBERG, R. (Orgs.). The Handbook of Economic Sociology. Princeton: Princeton University Press, 1994.

RUPPENTHAL, J. E.; CIMADON, J. E. O processo emprendedor em empresas criadas por necessidade. Gestão \& Produção, v. 19, n. 1, p. 137-149, jan. 2012.

SCHUMPETER, J. A. Teoria do Desenvolvimento Econômico: Uma Investigação sobre Lucros, Capital, Crédito, Juro e o Ciclo Econômico. São Paulo: Abril Cultural, 1982.

SCHUMPETER, J. A. Teoria do desenvolvimento econômico: uma investigação sobre lucros, capital, crédito, juro, e o ciclo econômico. São Paulo: Nova Cultural, 1997.

SHANE, S. Prior Knowledge and the Discovery of Entrepreneurial Opportunities. Organization Science, v. 11, n. 4, 2000.

SHANE, S.; VENKATARAMAN, S. The Promise of Entrepreneurship as a Field of Research. The Academy of Management Review, v. 25, n. 1, 2000.

SHEPHERD, D. Multilevel Entrepreneurship Research: opportunities for studying entrepreneurial decision making. Journal of Management, Thousand Oaks, v. 37, n. 2, p. 412-420, mar. 2011.

SILVA, M. A. O. M.; GOMES, L. F. A. M.; CORREIA, M. F. Cultura e Orientação Empreendedora: uma Pesquisa Comparativa entre Empreendedores em Incubadoras no Brasil e em Portugal. Revista de Administração Contemporânea, v. 13, n. 1, 2009.

ENOQUE, A. G.; BORGES, A. F. O espaço do domicílio como lócus da atividade empreendedora: um estudo sobre os empregadores domiciliares no Brasil contemporâneo. Revista de Empreendedorismo e Gestão de Pequenas Empresas, v. 3, n.1, p. 105-128, 2014. 
THORNTON, P. H. The Sociology of Entrepreneurship. Annual Review of Sociology, v. 25, 1999.

TRIPATHI, D. An Integrated View of Entrepreneurship. Economic and Political Weekly, v. 20, n. 48, 1985.

WEBER, Max. A Ética Protestante e o Espírito do Capitalismo. São Paulo: Pioneira, 2001.

Artigo recebido em: 06/09/2013. Artigo aprovado em: 17/04/2014 